\title{
Comparative Markedness and Opacity in Meskwaki Palatalization*
}

\author{
THOMAS R. WIER \\ University of Chicago
}

\section{Introduction}

Recent debates in phonological theory about the nature of opacity and its formal treatment have largely centered around the adequacy of output-oriented approaches such as Optimality Theory (Prince and Smolensky 1993) to capture the generalizations underlying opaque phenomena and yet at the same time maintain their architectural coherence. In this paper, I will attempt to show with data from Meskwaki (a.k.a. Fox; Algonquian) how one such approach within OT, Comparative Markedness (McCarthy 2002), not only requires certain problematic extensions of constraint ontogeny, but also results in contradictory rankings in handling palatalization and glide deletion processes in Meskwaki.

\section{The Data}

Meskwaki, also known as Fox, is an Algonquian language spoken by around 700 people on the Mesquakie settlement in Iowa (Grimes 1992). Like many Native American languages, it is characterized by an elaborate and complex system of morphosyntax. When it comes to phonological alternations, most processes seem to be morphologically restricted. Two of the few generalizations that seem to be purely phonologically conditioned can be found in (1).

$$
\begin{aligned}
& \text { Palatalization of /t/ before /i/ (Goddard 1994): }
\end{aligned}
$$

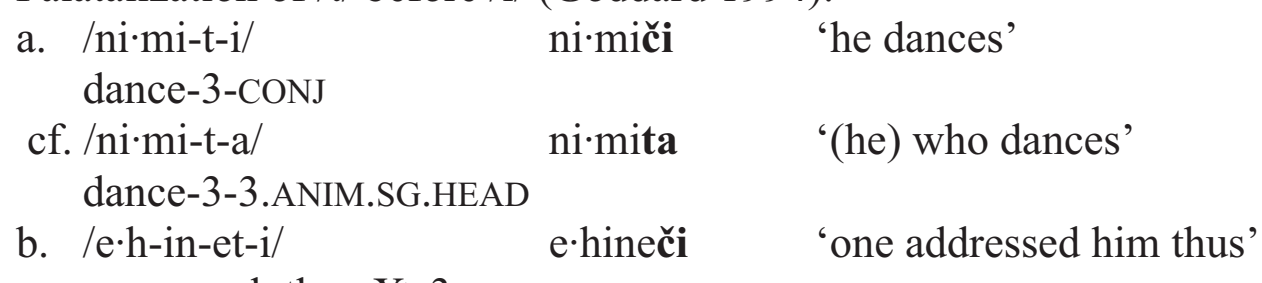

$$
\begin{aligned}
& \text { AOR-speak.thus- } \mathrm{X}>3-\mathrm{CONJ}
\end{aligned}
$$

\footnotetext{
* I would like to thank Amy Dahlstrom, Gunnar Hansson, Ives Goddard, John Goldsmith, Alan Yu, Adam Cooper, and Ilya Yakubovich for their discussion and responses to earlier versions of this paper. They are, of course, not to blame for any errors contained herein.
} 


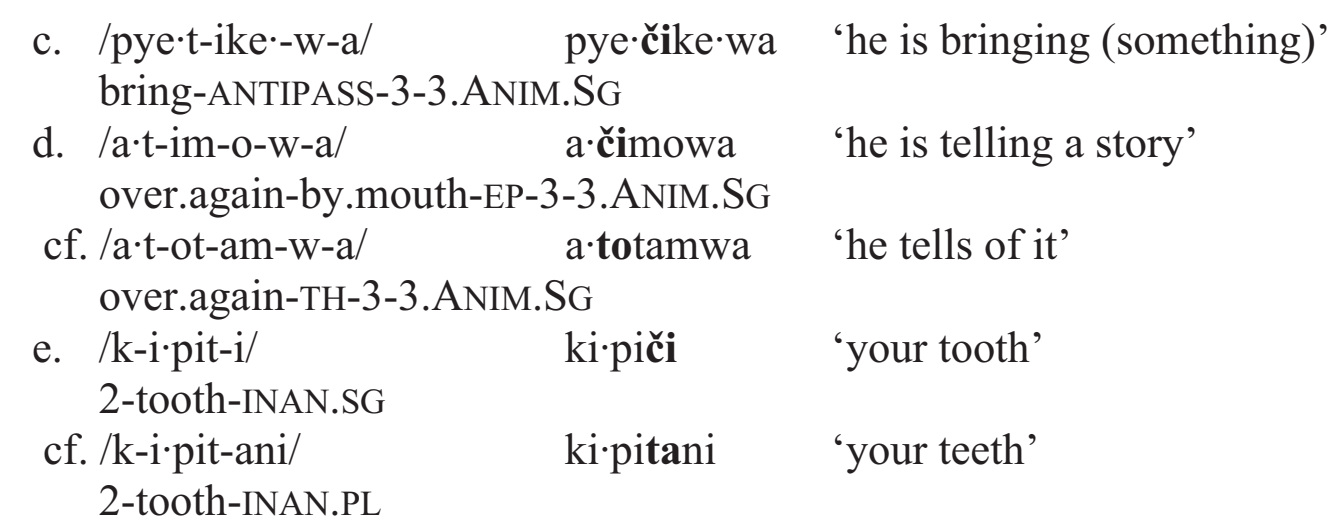

As the data in (1) illustrates, an underlying /t/ palatalizes to [č] before the high front vowel /i/. Thus, underlying /ni-mi-t-i/ 'he dances' surfaces as [ni-miči], in alternation with other related morphological forms like /ni-mi-t-a/ [ni-mita] '(he) who dances' where underlying / $t$ / remains because the conditioning environment for palatalization is not present. This palatalization occurs not just with derivational suffixes as in (1c-d), but also with various kinds of nominal and verbal inflectional suffixes, as in (1a), (1b), and (1e).

In contrast to this, this process of palatalization does not occur morphemeinternally, as shown in (2) below. Underlying /t/ appears only to palatalize to [ᄃ̌] in derived environments. Thus, although the $/ \mathrm{t} /$ in the reciprocal voice suffix -etiin (2a) has the right phonological conditioning environment, it fails to undergo palatalization to [č] because the /t/ does not surface near "new" information, i.e., at a morpheme boundary. Also like (1), this pattern is not restricted to a particular subset of the lexicon: derivational (2a, c, e), inflectional (2b), and verbal and nominal roots $(2 \mathrm{~d}, \mathrm{f})$ all show effects of this kind.

(2) Nonderived environment blocking:

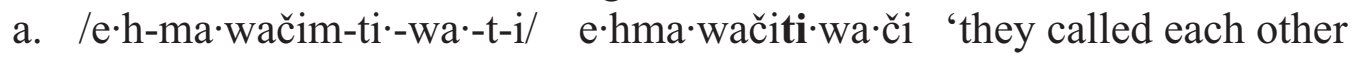 AOR-call.together-ANTIPASS-3PL-3-CONJ together'
b. /pašito h-etike/
pašito-hetike old.man-VOC.PL
c. /wača h-etiso-w-a/ wačahetisowa cook-REFL-3-3.ANIM.SG
wača'hetisowa 'he is cooking for himself'
ti·kwe $\cdot$ wi
'it patters'
'old men!' (voc. pl.)
d. /ti kwe--w-i/ patter-3-3.INAN.SG
e. /kišk-itiy-e--w-a/ fall.off-tail-TH-3-3.ANIM.SG
g. -eti-
h. -etiso-
i. -etike-
f. /taneti-w-aki/ kiškitiye $\cdot w a$
'his tail falls off' gamble-3-3.ANIM.PL taneti·waki
'they gamble, make bets' reciprocal suffix middle voice suffix vocative


(2a) is particularly striking, because it shows that the palatalization process may occur to one sequence of $/ \mathrm{ti} / \mathrm{in}$ a word even when another sequence of $/ \mathrm{ti} / \mathrm{in}$ the same word fails to undergo palatalization because it is morpheme-internal. Nonderived environment blocking of this sort has been reported in many languages. But on top of this, there is a separate and synchronic (Ives Goddard, p.c.) process of glide deletion in (3) which can bring about phonological contexts identical to those in (2) and which, in derivational terms, counterfeeds palatalization:

(3) Counterfeeding opacity:
a. /nekotw-ičiše/ one-inch
cf. /nekotw-ayaki/ one-group
b. /na-nekotw-i/ RED-one-PART
c. /očity-i/ bird's.tail-3.Inan.Sg
cf. /očity-ani/ ${ }^{1}$ bird's.tail-3.INAN.PL
d. /pe·škity-i/ basket-3.INAN.SG
cf. /pe-škity-ani/ basket-3.INAN.PL

\begin{tabular}{|c|c|}
\hline nekotičiše & 'one inch' \\
\hline nekotwayaki & 'one group' \\
\hline na.nekoti & $\begin{array}{l}\text { 'one apiece, one by } \\
\text { one' }\end{array}$ \\
\hline očiti & 'bird's rump or tail' \\
\hline očitye·ni & 'bird's tails' \\
\hline pe $\cdot \breve{s} k i t i$ & 'basket' \\
\hline pe·škitye·ni & 'baskets' \\
\hline
\end{tabular}

This process brings about surface sequences of [ti] which do not underlyingly qualify as morphologically driven blocking of palatalization, because a glide such as $/ y /$ or $/ w /$ stands in the way of that morphological edge. And yet when glide deletion prevents these from surfacing in the output, it has the same effect as if the /t/ were underlyingly at a morpheme boundary. We may summarize these effects in (4) below.

(4) Summary of above phonological generalizations in Meskwaki:

\begin{tabular}{|c|c|c|c|}
\hline Palatalization & $/ \mathrm{ni} \cdot \mathrm{mi}-\mathrm{t}-\mathrm{i} /$ & ni·miči & 'he dances' \\
\hline $\begin{array}{l}\text { Nonderived } \\
\text { environment } \\
\text { blocking }\end{array}$ & /e'h-ma·wačim-ti·-wa'-t-i/ & e'hma·wačiti·wa·či & $\begin{array}{l}\text { 'they called } \\
\text { each other } \\
\text { together' }\end{array}$ \\
\hline Glide deletion & /nekotw-ičiše/ & nekotičiše & 'one inch' \\
\hline
\end{tabular}

\footnotetext{
${ }^{1}$ It is not altogether certain that $t y$-stems are synchronically /ty + ani/, rather than $/ \mathrm{t}+\mathrm{ye} \cdot \mathrm{ni} /$ (Ives Goddard, p.c.), but as the $t w$-stems show, throwing out these forms would not get rid of the underlying problem. To complicate matters further, ty-stems sometimes do cause palatalization; for fuller details, see Goddard (2001).
} 
We are faced with not simply having to account formally for how the morphological status of affixes affects the palatalization process, but also for why a completely unrelated process in this language, glide deletion, brings about the same kind of surface structure which is otherwise illicit. Any theoretical account of phonological opacity such as this must be able to capture this many-to-one relationship between processes and surface outputs.

\section{The Architecture of Comparative Markedness}

Classical derivational phonology, which like Optimality Theory assumed that all phonologically conditioned allomorphy should be handled by some synchronic phonological module, could approach this kind of situation with ease, and indeed that was one of the primary reasons advanced in favor of extrinsic rule ordering (Kiparsky 1968). Unlike intrinsic rule ordering, where processual interaction is held constant cross-linguistically, extrinsic rule ordering makes the prediction that, from the vantage point of the surface, languages may vary in how certain processes interact or not. Thus in Meskwaki, palatalization must logically ${ }^{2}$ precede glide deletion, so that /ni-mi-t-i/ 'he dances' would palatalize to ni-miči while at that same logical step, a form like /nekotw-ičiše/ 'one inch' would not provide the palatalization rule the appropriate licensing environment. When the logically secondary glide deletion rule came into effect, the palatalization process could no longer have any say over sequences of [ti], thus leaving them as such in the output.

But having to work with a two-level mapping of input and output, the theory of Comparative Markedness (CM) cannot account for such facts so directly. The basic departure of CM from early work in OT is that the family of Markedness constraints is broken down into two separate yet intimately related families of Markedness constraints which are respectively sensitive only to "new" or only to "old" information relative to the input. Like all OT accounts, the GEN function creates a set of possible output candidates each of whose properties are assessed by a ranked hierarchy of constraints. Unlike most accounts in OT, however, one candidate, the Fully Faithful Candidate (FFC), ${ }^{3}$ is given a privileged position within the candidate set, in that Markedness constraints now must take into account not just potential violations of a given candidate itself, but also whether that candidate shares that same violation with the FFC. McCarthy (2002) defines it in the following way:

\footnotetext{
${ }^{2}$ How such computations were actually mentally arrived at never gained anything resembling a consensus during early debates about generative phonology.

3 The FFC is used, rather than direct reference to the input, because the FFC might contain completely predictable information such as syllabification not present in the underlying representation.
} 
"These novel markedness constraints distinguish between:

a. Mappings that fail to correct a marked configuration in the FFC. E.g., the mapping $/ \mathrm{ab} / \rightarrow ? a b$ fails to correct the marked voiced obstruent in the FFC $a b$. That is, the NOVCDOB [No-Voiced Obstruent-TRW] violation in $P a b$ is 'old' because the fully faithful candidate $a b$ has the same violation; and

b. Mappings that introduce new marked configurations. E.g., the mapping /ampa/ $\rightarrow$ amba (i.e., post-nasal voicing) introduces a voiced obstruent that is not present in the FFC ampa. That is, the NoVCDOB violation in $a m b a$ is 'new' because the fully faithful candidate ampa doesn't have this violation." (McCarthy 2002:2)

Because markedness phenomena are no longer governed by a single theoretical construct — namely, by a single markedness constraint — but rather by two, the practical difference between a CM view of constraint ontology and the more traditional kind seen in OT can be realized only when some other constraint, usually a faithfulness constraint, intervenes between the two kinds of markedness constraints. McCarthy is able to derive a number of different kinds of phonological phenomena from opposite rankings of new and old constraints, as seen in (6):

$$
\text { a. }{ }_{\mathrm{N}} \mathrm{M}>>\mathrm{F}>>{ }_{0} \mathrm{M} \text { : grandfather effects, derived environment effects (DEEs) }
$$

b. ${ }_{0} \mathrm{M} \gg>\mathrm{F}>>{ }_{N} \mathrm{M}$ : noniterating processes, coalescence paradoxes, counterfeeding opacity

A number of these phenomena have proven thorny for many earlier theories of phonology, and not just with opaque processes. DEEs and noniterating processes had required some notion of cyclic derivations within lexical phonology to constrain the effects of powerful rewrite rules. At the same time, another merit of $\mathrm{CM}$ is that it makes a clear prediction about constraint interaction. This is that an epiphenomenon of one ranking may not with the same set of CM constraints in the same hierarchy bring about surface forms that ought properly to be epiphenomena of the opposite ranking. That is, we should not expect to see a process that is subject to both, say, derived environment effects and counterfeeding opacity. This is a strong claim, and a desirable outcome of the architecture of any linguistic theory, because it can be directly tested by reference to new data and be thereby potentially falsified. ${ }^{4}$

Unfortunately for CM, as the Meskwaki data show, precisely such phonological systems do exist, indeed, in a situation very similar to that discussed by McCarthy using palatalization in Korean, as in (1) and (2) above:

\footnotetext{
${ }^{4}$ Of course, no synchronic theory can be proved correct as such; theories may only be disproven.
} 

a. $/$ pat $^{\mathrm{h}}-\mathrm{i} /$
pac $^{h_{i}}$ 'field-COP'
/mat-i/
$/$ put $^{\mathrm{h}}-\mathrm{i} /$
maci 'eldest-NOM'
/tot-i/
puc $^{\mathrm{h}_{i}}$ 'to stick to-CAUS'
b. /mati/
toci 'rise-NOM'
cf. $/ \mathrm{kac}^{\mathrm{h}} \mathrm{i} /$
mati 'knot'
kac $^{h_{i}}$ 'value' (McCarthy 2002:23)

Here, /t/ palatalizes to /c/ before underlying /i/, as in mat-i 'eldest-NOM', but not when a phonologically identical string of segments has no internal morpheme boundary, as in (7b) mati 'knot'. Because DEEs constitute generalizations across paradigms and because inflectional morphemes by definition are never realized separately from the stems to which they are attached, McCarthy invokes the notion within Correspondence Theory of output-to-output correspondence. In this approach, an output form may be judged according to not just the potential constraint violations arising from its own input (i.e., from input-to-output correspondence), but also the potential violations arising from some other morphologically related form. This is in effect a kind of formalization of analogical processes. McCarthy layers this contrast in correspondence over the new and old markedness constraints to derive a four-way typology of constraints: IO- ${ }_{N} \mathrm{PAL}, \mathrm{IO}{ }_{\mathrm{O}} \mathrm{PAL}, \mathrm{OO}{ }_{\mathrm{N}} \mathrm{PAL}$, and $\mathrm{OO}{ }_{\mathrm{O}} \mathrm{PAL}$, three of which will prove crucial to explaining the DEEs seen in Korean. These may be formally defined as follows:

Constraint definitions:

a. IO-oPAL: incurs one violation $(*)$ for every locus of [ti] present in the FFC of the underlying representation of the word in IOcorrespondence

b. OO- ${ }_{0} \mathrm{PAL}$ : incurs one violation $(*)$ for every locus of [ti] present in the FFC of the underlying representation of the form in OOcorrespondence

c. OO- ${ }_{\mathrm{N}} \mathrm{PAL}$ : incurs one violation $(*)$ for every locus of [ti] not present in the FFC of the underlying representation of the form in OOcorrespondence.

d. IDENT: input features must be present in output, and vice versa

To bring about the DEEs of Korean, the constraint OO- ${ }_{\mathrm{N}} \mathrm{PAL}$ must be ranked above IDENT to impose palatalization in forms like tot- $i$ [toci] 'rise-NOM' where the form in OO-correspondence, tot, has no locus of [ti] and thus nothing to enforce identity. Yet IDENT must be ranked above IO- ${ }_{0} \mathrm{PAL}$ and $\mathrm{OO}{ }_{0} \mathrm{PAL}$ to ensure that loci of [ti] in the FFC of the underlying representation of forms like mati 'knot' do not at the same time palatalize, since there is no form in OOcorrespondence which does not have [ti] and thus no form relative to which the 
output candidate [mati] is marked. These relations are shown in the tableau in $(9)^{5}$ :

(9) Korean: OO-NPAL $>$ IDENT $>>$ IO-oPAL, OO-oPAL

\begin{tabular}{|c|c|c|c|c|}
\hline /tot/ & OO-NPAL & IDENT & IO-oPAL & OO-oPAL \\
\hline \multicolumn{5}{|l|}{ a. tot (FFC) $\diamond$} \\
\hline b. toc & & $* !$ & & \\
\hline \multicolumn{5}{|l|}{ /tot-i/ } \\
\hline c. toci $\diamond$ & & $*$ & & \\
\hline d. toti (FFC) & $* !$ & & $*$ & \\
\hline \multicolumn{5}{|l|}{ /mati/ } \\
\hline e. mati (FFC) $\diamond$ & & & $*$ & $*$ \\
\hline f. maci & & $* !$ & & \\
\hline
\end{tabular}

\section{Meskwaki DEEs and Counterfeeding Opacity}

Formally, this situation is so far identical to our situation in Meskwaki: underlying /t/ palatalizes to /č/ before only those /i/'s which do not constitute part of the same morpheme. We could formalize this with the tableau in (10):

\begin{tabular}{|c|c|c|c|c|}
\hline /ni-mi-t-a/ & $\mathrm{OO}-\mathrm{NPAL}$ & IDENT & IO-oPAL & OO-oPAL \\
\hline \multicolumn{5}{|l|}{ a. ni.mita (FFC) $\diamond$} \\
\hline b. ni·miča & & $* !$ & & \\
\hline \multicolumn{5}{|l|}{ /ni·mi-t-i/ } \\
\hline c. ni·miči $\diamond$ & & $*$ & & \\
\hline d. ni·miti (FFC) & $* !$ & & $*$ & \\
\hline \multicolumn{5}{|l|}{ /pašito'h-etike/ } \\
\hline e. pašito hetike (FFC) $\diamond$ & & & $*$ & $*$ \\
\hline f. pašito hečike & & $* !$ & & \\
\hline
\end{tabular}

In (10a-b), candidate (a) ni.mita is selected as most optimal because (b) $n i \cdot m i c ̌ a$ contains a gratuitous violation of IDENT where no locus of /ti/, underlying or otherwise, motivates it. Likewise, although (10d) ni.miti does not have any IDENT violations, it does contain loci of [ti] relative both to its FFC (i.e., itself) and to the FFC in (10a) ni.mita with which it stands in OO-correspondence. Thus it violates both $\mathrm{OO}{ }_{-} \mathrm{PAL}$ and $\mathrm{IO}{ }_{-} \mathrm{PAL}$. It does not violate $\mathrm{OO}{ }_{-} \mathrm{PAL}$ because $(10 \mathrm{a})$ ni.mita contains no locus of [ti], and thus cannot share that marked feature with (10d) ni·miti.

\footnotetext{
${ }^{5}$ I have taken over the formatting of this tableau directly from McCarthy (2002:24).
} 
The DEE becomes clear when we look at (10e-f). Because the locus of [ti] in pašito hetike is internal to the morpheme, the only possible OO-correspondence that this morpheme can have is with itself. This implies that no violation of $\mathrm{OO}_{-\mathrm{N}} \mathrm{PAL}$ is possible, since all loci of [ti] will be shared with the same FFC. The output form thus naturally falls out from the constraint hierarchy, since (10f) pašito hečike does violate IDENT even though it does not violate the lower ranked constraints $\mathrm{IO}{ }_{\mathrm{O}} \mathrm{PAL}$ and $\mathrm{OO}{ }_{\mathrm{O}} \mathrm{PAL}$, and thus the less marked form in (10e) pašito hetike is selected by the EVAL algorithm.

The area that poses difficulties for the CM account of opacity, as mentioned above, is that Meskwaki also has a glide deletion process which can create loci of [ti] which however are both phonologically and morphologically "derived" at the same level of the lexicon. According to McCarthy's conception of $\mathrm{CM}$, however, counterfeeding opacity can only come about as a result of the interaction of CM constraints if "old" constraints outrank "new" constraints. To illustrate this, the ranking in (11) is needed:

$$
\text { *GLIDE }>>\text { OO-O PAL }>>\text { IDENT }>>\text { IO-O }{ }_{-} P A L, \text { OO-N PAL }
$$

\begin{tabular}{|l|c|c|c|c|c|}
\hline \multicolumn{1}{|c|}{$/$ na-nekotw-i/ } & ${ }^{*}$ GLIDE & OO-oPAL & IDENT & IO-oPAL & OO-NPAL \\
\hline \hline a. na.nekotwi (FFC) & $* !$ & & & & \\
\hline b. na.nekoti $\diamond$ & & & $*$ & & $*$ \\
\hline c. na.nekoči & & & $* * !$ & & \\
\hline \hline /nekotw-ayak-i/ & & & & & \\
\hline d. nekotwayaki $\diamond$ & & & & & \\
\hline e. nekotayaki & & & $* !$ & & \\
\hline
\end{tabular}

The candidate in (11a) na.nekotwi is eliminated on the grounds that it contains an unlicensed glide in the onset with $/ \mathrm{t} /$, so the choice falls to (11b) na.nekoti or (11c) na.nekoci . Both candidates delete the underlying glide, but because (11c) na.nekoč $i$ both deletes this glide and changes the continuancy features on the preceding stop, it incurs a higher number of violations of IDENT relative to (11b) na.nekoti. That is, CM is capable of handling counterfeeding opacity as such, but only when it does not occur in the context of processes like DEEs derived from the contrary constraint ranking.

\section{Implications}

The fact that Meskwaki directly contradicts one central prediction of CM does not deal a death blow to the theory as such. One might claim that CM would still be useful to handle various sorts of processes like DEEs or grandfather effects that have proven awkward for earlier generative theories of phonology. But some mechanism - e.g., a kind of universal hierarchy that "new" always outranks "old" or vice versa-would have to be invoked to prevent the effects of the reverse constraint ranking from imposing contradictory results as in the Meskwaki data. 
This would mean, to be sure, that the various phenomena that have been claimed to come under its ambit would not, after all, be able to be unified in the same way. Probably more importantly, this just raises larger issues about what CM and phonological theory at large are supposed to be doing in the first place. If CM can only work by effectively doubling the number of theoretical entities in the form of a new subfamily of constraints and needs peculiar mechanisms to make sure that it does not work itself into a contradiction, this opens the question of whether some simpler formalism might be able to capture the same generalizations at lesser cost. The answer to this depends in part on what one takes to be part of the speakers' synchronic grammar. If it could be shown that that in Meskwaki either the DEEs or the counterfeeding opacity were the result of diachronic changes that are no longer really a part of the speakers' internalized grammars - or to put it differently, the problem is synchronically a morphological, not a phonological, question - then our problem could be waved away. This is potentially the case with $t y$-stems in (3c-d), but $t w$-stems suggest that there must be a real synchronic element to this. As things stand, a great deal more research on modular interaction within languages like Meskwaki is needed.

\section{References}

Goddard, Ives. 1994. Leonard Bloomfield's Fox Lexicon: Critical Edition. Winnipeg, Manitoba: Algonquian and Iroquoian Linguistics.

Goddard, Ives. 2001. Contraction in Fox (Meskwaki). In J. D. Nichols, ed., Actes du Trente-Deuxième Congrès des Algonquinistes. Winnipeg, Manitoba: The University of Manitoba Press.

Grimes, Barbara F., ed. 1992. Ethnologue:Languages of the World. Summer Institute of Linguistics.

Kiparsky, P. 1968. How abstract is phonology? Bloomington: Indiana University Linguistic Club. [Reprinted in O. Fujimura, ed. 1973. Three Dimensions of Linguistic Theory, 5-56, Tokyo: TEC.]

McCarthy, John. 2002. Comparative markedness. Ms., University of Massachusetts, Amherst. [ROA-489]

Prince, Alan, and Paul Smolensky. 1993. Optimality Theory: Constraint Interaction in Generative Grammar. RuCCs Technical Report \#2, Rutgers University Center for Cognitive Science, Piscataway, New Jersey.

Department of Linguistics

University of Chicago

1010 E. $59^{\text {th }}$ Street

Chicago, IL 60637, USA

trwier@uchicago.edu 